\title{
Cidade/Urbano versus Campo/Rural: A NECESSIDADE DE POLÍTICAS PÚBLICAS QUE SUPEREM ESTA DICOTOMIA PARA INCLUSÃO DAS POPULAÇÕES POBRES NO BRASIL
}

City/Urban versus Rural/Countryside: The Necessity of Public Policies that Overcome this Dichotomy for the Inclusion of the Poor Populations in Brazil

Ciudad/Urbano versus Campo/Rural: la necesidad de políticas públicas que superen esta dicotomia para la inclusión de las poblaciones pobres en Brasil

\section{Thiago Sebastiano de Melo sebastianodemelo@gmail.com Universidade Federal de Goiás}

RESUMO: O Brasil deixou de ter a maioria da população a residir no campo na década de 60. Atualmente, segundo dados do Instituto Brasileiro de Geografia e Estatística - IBGE, mais de $80 \%$ da população vive em cidades. Todavia, no Brasil a definição de perímetro urbano e rural é dada pelo poder legislativo municipal e não por critérios como densidade demográfica, infraestruturas "urbanas" etc., o que faz com que não existam parâmetros nacionais que permitam definir e tratar as cidades como construções sociais sendo, antes, instrumentos de negociação política. Se por um lado o país conta com algumas das cidades mais populosas do mundo, por outro lado a realidade da maior parte dos municípios brasileiros é completamente distinta. Apontar os principais efeitos desta estruturação na definição de cidade, em detrimento do campo, para o conjunto da população, bem como refletir em que medida as políticas públicas podem ser um mecanismo de garantia dos direitos constitucionais para o conjunto da população brasileira é o objetivo deste trabalho. A revisão bibliográfica acerca dos conceitos de modernidade, cidade, cidadania, urbano/ urbanização, campo, rural/ruralidade permite situar o Brasil no contexto do 
crescimento urbano e concentração de rendimentos, portanto, da necessidade de inclusão da população mais pobre e vulnerável.

Palavras-Chave: cidade-campo; modernidade; cidadania; políticas públicas.

ABSTRACT: Since the 1960s, the majority of Brazil's population no longer lives in the countryside. According to data from the Instituto Brasileiro de Geografia e Estatística, more than $80 \%$ of the population now lives in cities. However, in Brazil defining the urban-rural perimeter is the legal responsibility of local municipalities, and criteria such as demographic density, "urban" infrastructure, etc, are not taken into account. As a result, there are no national parameters that allow and treat cities as social constructions, thus turning them into political bargaining chips. While the country has some of the most populous cities in the world, the reality is that most Brazilian cities are much smaller. The main aims of this paper are to highlight the principle effects of this mechanism on the definition of the city, in detriment to the countryside, for a whole population, and to reflect on how far public policies can guarantee the constitutional rights for all Brazilians. The review of the literature on the concepts of modernity, the city, citizenship, urbanism/urbanization, countryside, rural/rurality situates Brazil in the context of urban development and income concentration and, therefore, highlights the need to include its most vulnerable and poorest citizens.

KeY words: City-Countryside, Modernity, Citizenship, Public Policies.

RESUMEN: Brasil dejó de tener la mayoría de la población residente en el campo en los años 60. Hoy en día, según datos del Instituto Brasileño de Geografía y Estadística (IBGE), más del $80 \%$ de la población vive en las ciudades. No obstante, en Brasil la definición de perímetro urbano y rural está dada por el poder legislativo municipal y no por criterios como densidad demográfica, infraestructura urbana, etc., lo que causa la falta de parámetros nacionales que permitan y traten a las ciudades como construcciones sociales, y los convierten así en medios de negociación política. Mientras que el país tiene algunas de las ciudades más populosas del mundo, la realidad de la mayor parte de 
las ciudades brasileñas es completamente distinta. Destacar los principales efectos de este mecanismo en la definición de una ciudad, en detrimento del campo, para el conjunto de una población, así como reflejar hasta qué punto las políticas públicas pueden ser un mecanismo de garantía de los derechos constitucionales para el conjunto de la población brasileña es el objetivo principal de este proyecto. La revisión bibliográfica sobre los conceptos de modernidad, ciudad, ciudadanía, urbanismo/urbanización, campo, rural/ruralidad permite situar a Brasil en el contexto del desarrollo urbano y la concentración de los ingresos, por lo tanto, la necesidad de incluir a la población más vulnerable y pobre.

Palabras clave: ciudad-campo, modernidad, ciudadanía, políticas públicas.

RESUM: Brasil va deixar de tenir la majoria de la població resident al camp en els anys 60. Avui en dia, segons dades de l'Institut Brasiler de Geografia i Estadística (IBGE), més del $80 \%$ de la població viu a les ciutats. Això no obstant, al Brasil la definició de perímetre urbà i rural està donada pel poder legislatiu municipal i no per criteris com densitat demogràfica, infraestructura urbana, etc., la qual cosa causa la manca de paràmetres nacionals que permeten i tracten les ciutats com construccions socials, i els converteixen així en mitjans de negociació política. Mentre que el país té algunes de les ciutats més populoses del món, la realitat de la major part de les ciutats brasileres és completament diferent. Destacar els principals efectes d'aquest mecanisme en la definició d'una ciutat, en detriment del camp, per al conjunt d'una població, així com reflectir fins a quin punt les polítiques públiques poden ser un mecanisme de garantia dels drets constitucionals per al conjunt de la població brasilera és l'objectiu principal d'aquest projecte. La revisió bibliogràfica sobre els conceptes de modernitat, ciutat, ciutadania, urbanisme/urbanització, camp, rural/ruralitat permet situar al Brasil en el context del desenvolupament urbà i la concentració dels ingressos, per tant, la necessitat d'incloure a la població més vulnerable i pobre.

Paraules ClaU: ciutat-camp, modernitat, ciutadania, polítiques públiques. 


\section{Introdução}

$\mathrm{O}$

Brasil tem uma história rural. Há muito tempo que a reorganização do campo e da cidade tem sido sobredeterminada por um projeto de modernização (Mendonça, 2015; Chaveiro \& Calaça, 2012; Castilho, D. \& Chaveiro, 2010; Brandão, 2007; Carneiro, 1998). A população brasileira até meados da década de 60 era maioritariamente rural. Esta estreita ligação entre a população e o rural permite e exige muitas análises, tanto sobre a sua influência contemporânea como sobre a causa e a consequência da sua rutura/ reversão.

Um dos elementos centrais dessa questão, no tocante às políticas públicas, certamente é a caracterização da área urbana e da área rural que, consequentemente, define a população residente nestas duas áreas. Ao esbater, ou seja, não tornar claro os parâmetros do que é urbano e do que é rural, adotando uma definição administrativa definida pelo poder legislativo municipal, o Estado nacional complica a formulação de políticas públicas que criem e mantenham condições para viver bem no campo. ${ }^{1}$

A pertinência desta leitura é evidenciada, por exemplo, com a adoção a partir do ano corrente (2017) de novos critérios para definição de urbano e rural (IBGE, 2017). Sem entrar no mérito dos parâmetros utilizados, ${ }^{2}$ bem como das categorias derivadas, o facto de se proceder a uma análise mais criteriosa (para além de aceitar a definição de ordem municipal, subjugada ao jogo político local) baixou a taxa da população urbana de $84,4 \%$ para $76 \%$.

Ao mesmo tempo que a população que vive no campo é preterida pelas políticas públicas, essa mesma dinâmica de exclusão reforça, de modo impositivo e mobilizando todos os aparelhos ideológicos do Estado, a ideia de que a urbanização é a consolidação do processo de crescimento económico e desenvolvimento social. Assim, afirmando essa dinâmica sem problematizar as suas contradições e o direito de populações rurais terem garantidas as condições para a sua reprodução social, a urbanização, como conteúdo do desen-

1. Para fins didáticos, assumimos Campo e Rural(idade) como o par forma-conteúdo oposto à Cidade-Urbano(idade).

2. Ressalta-se que na nossa análise tais parâmetros são insuficientes para dar a real dimensão da vida rural no Brasil. 
volvimento, acabar por negar os diversos territórios e os diversos sujeitos que vivem no campo 3 (Lima, 2005; Carneiro, M.,1998).

A tese que se depreende, portanto, já é conhecida: a modernização como horizonte da urbanização naturaliza e legitima a exclusão do campo, como explicitam os estudos, por exemplo, de M. Carneiro (1998) e E. Lima (2005). Daí a razão pela qual a Organização das Nações Unidas (ONU) na sua Conferência sobre Moradia e Desenvolvimento Urbano Sustentável, com o intuito de definir ações para o desenvolvimento mundial, estabelece uma Nova Agenda Urbana (com base na qual o IBGE reviu sua caracterização de urbano e rural).

Neste caso, é a visão de quem vive a primeira relação espaço geográfico/tempo histórico - dos estágios mais avançados de tecnologia, de urbanidade - que determinam discursos e "projetos" de vida de si e dos outros. É esse discurso que tem validade sobre a vida das coletividades denominadas tradicionais. Estas tendem a acreditar no que é dito sobre elas, e fazem disso seu próprio discurso. [...] Da mesma maneira, os que vivem na tradição (movimento transformação conduzido pela permanência) não nomeiam e nem criam significados de sua realidade. (Campos, 2014, p. 52)

Deste modo, pretende-se demonstrar como a narrativa e a "prática" do desenvolvimento/modernização, no Brasil, segrega segmentos inteiros da população, urbana e rural, bem como a intersecção social destes segmentos em ambos os contextos geográficos.

Concordando com M. Santos (2008) e D. Castilho (2016) de que existem modernizações e não uma única modernização, nota-se a influência de sujeitos coletivos que concorrem para a implantação dessa modernização contemporânea no país.

A chamada revolução verde, também conhecida como modernização do campo, foi a consolidação de um projeto de país cujas duas principais faces foram a urbanização/agroindustrialização do campo e a expropriação camponesa (Brandão, 2007; Mendonça, Thomaz Junior, 2004), ou, de forma mais ampla, dos sujeitos que residem nestes territórios. É próprio do capitalismo, como evidenciou Harvey (2011), expropriar camponeses em todo o mundo

3. Se não fosse fugir do âmbito da proposta, caberia arrolar notas críticas ao alinhamento da postura do IBGE, mesmo na sua nova proposta de caracterização do urbano e do rural, às sobredeterminações "modernizadoras" que implicam a exclusão do rural. 
em sua expansão. Acontece, todavia, que no Brasil isso não só foi naturalizado, como ganhou contornos muito peculiares.

Fundindo os interesses de uma elite nem um pouco patriótica, amálgama de capitalistas nacionais e internacionais com latifundiários nacionais, com a narrativa de que desenvolver socialmente é urbanizar/industrializar, o Estado brasileiro cria e legitima as bases para que esse projeto de país prossiga.

A síntese desse projeto para o campo é o agronegócio. No Brasil, essa forma particular de intervenção do capital transnacional conduz à já velha e conhecida confusão (intencional) entre desenvolvimento social e crescimento económico (Lefebvre, 1979).

Os representantes parlamentares do agronegócio no Brasil estão agrupados na Frente Parlamentar Agropecuária, popularmente conhecida como bancada ruralista. É a maior bancada do Congresso Nacional. Com aval e apoio das corporações mediáticas hegemónicas, de empresários ligados ao setor e do poder judiciário e executivo, impuseram ao país a ideia de que o campo não é mais um local de moradia digna, e sim de produção, bem como de que o problema da fome e do crescimento económico nacional serão resolvidos com a maquinização e a inserção de fatores de produção agroquímicos no processo produtivo rural. Com isso, negam a necessidade de uma reforma agrária e expropriam e expulsam as populações que "impedem" o pleno desenvolvimento desse projeto (Araújo, 2017).

O objetivo central desse texto é demonstrar que a definição de cidade-urbano e campo-rural no Brasil não está ligada aos interesses populares. Está, antes, subordinado a um projeto de sociedade mais amplo, que podemos definir como urbano-capitalista. Em decorrência da execução e manutenção desse projeto, segmentos sociais definidos (camponeses, negros, mulheres e população pobre) têm tido os seus direitos constitucionais (garantidos pela Constituição Federal de 1988 e, de forma mais ampla, por tratados internacionais dos quais o Brasil é signatário) negados sistematicamente (Carvalho, Ribas, Benitez, 2017). Essa intersecção entre classe, raça e género termina por punir de modo ainda mais perverso quem vive no campo. 


\section{Modernização, o esvaziamento do campo}

As políticas públicas são mecanismos de ajustamento de desequilíbrios sociais e não são de exclusividade do poder público. Muito embora tenham grande dependência deste, na realidade, as políticas públicas também podem ser operacionalizadas pela iniciativa privada e pela sociedade civil (SECCHI, 2010). Elas constituem as bases para que se consolide um projeto de país.

Para entender, portanto, como e por que razão as atuais políticas públicas brasileiras continuam a apostar numa modernização que precariza e exclui a população pobre do campo e da cidade (Oxfam, 2017; Cerqueira et al., 2017), olhemos para a história de uso e ocupação do território nacional.

O Brasil foi colonizado no século XVI e desde então tem desempenhado uma função de exportador de matéria-prima, designadamente voltada para alimentação e extração mineira. Esse papel imposto pela colónia portuguesa e reforçado pelo capitalismo após a independência do país permitiu que se naturalizasse um discurso de uma vocação brasileira como celeiro e exportador de minerais para o mundo. Essa dupla função, pintada com cores nobres, uma vez que garantir alimentação para o mundo para combater um alarmante quadro de fome, bem como os minerais para que o capitalismo continue avançando, tem sido insistentemente reforçada pelo Estado (Pessoa, 1988).

A pauta exportadora do Brasil no que toca ao campo é eminentemente voltada para "commodities" e tem muito pouco a ver com alimentação diversificada e com um compromisso que assegure o desenvolvimento social igualitário, interno e dos demais países, sobretudo, em desenvolvimento.

Para assegurar o seguimento desse roteiro é preciso ter acesso às jazidas minerais e amplas áreas, uma vez que a produção de "commodities" agrícolas se dá por meio de monoculturas que exigem maquinaria e fatores e produção agroquímicos que são mais rentáveis quando utilizados em grandes extensões de uma única cultura.

Os espaços nos quais é possível realizar plantações contadas aos milhares de hectares e com acesso às jazidas minerais não estão vazios, no entanto. São, antes, regra geral, território de populações muito diversas. Algumas, como as Populações Tradicionais, residem há séculos nestes territórios. Por que, então, se a permanência em seus territórios é um direito constitucional, 
não há um esforço do Estado para garantir que tais populações permaneçam nestes locais? Porque é preciso modernizar!

A modernidade, consagrada com a revolução industrial, construiu uma narrativa para a sociedade. Tem um sujeito próprio, uma racionalidade que a valida e um propósito nobre. O sujeito da modernidade é o homem branco, cristão, heterossexual e bem-sucedido economicamente. A racionalidade que avaliza a modernidade é científica e tecnológica. E o seu propósito é que, a partir do conhecimento científico e desenvolvimento tecnológico, se alcance o crescimento económico que se converterá em desenvolvimento social.

Os rebatimentos da modernidade para o território são conhecidos (D. Castilho, 2011, Mendonça, 2004). O que é preciso ressaltar neste momento é que tanto no Brasil como nos demais países, inclusive os chamados desenvolvidos, a subjugação dos outros sujeitos, que não esse consagrado pela modernidade, foi assombrosa até ao século xx. Com o movimento feminista, avanços em acordos internacionais de garantia dos Direitos Humanos, e mesmo o acumular das experiências históricas de contestação a esse projeto social, alguns países construíram políticas de inclusão destes sujeitos, garantindo direitos essenciais. Entretanto, a violência continua a ser um elemento central da imposição desse projeto, que continua em expansão no Brasil (Cerqueira et al., 2017).

$\mathrm{Na}$ segunda metade do século passado, a revolução verde chegou ao Brasil com a promessa de levar tecnologia e conhecimento científico para o campo, o que garantiria crescimento económico e desenvolvimento social. No mesmo momento histórico, o país está a consolidar a sua industrialização nas grandes áreas urbanas e precisa de mão de obra barata.

A soma do discurso de que a modernidade reside na cidade-urbano e de que é preciso transformar o campo num grande produtor de "commodities" avaliza um processo de expropriação e expulsão das populações rurais, que passam a migrar para a cidade, enchendo-as e iniciando um processo de crescimento das grandes periferias e favelas, cujas grandes características são a não-presença do Estado, o que se reflete na falta de acesso a direitos básicos, como educação, saúde, habitação condigna e saneamento básico. 
Esse momento do país crava um símbolo na imagem coletiva: o Brasil deixa de ser um país agrário/rural e passa a ser um país moderno, com grandes cidades, altamente urbanizado e com crescente industrialização. Ou seja, o projeto está a dar certo! Mas ainda é preciso continuar a expandir o território do agronegócio. E para tal, é preciso retirar os sujeitos que resistem às táticas de convencimento e/ou expulsão, mesmo recorrendo violência física resultante em mortes (Mitidiero Junior, 2017). É o ónus do progresso rumo à modernidade!

Com a população rural a diminuir abruptamente e grande parte da população nacional a residir agora em áreas urbanas, segundo os dados oficiais, cabe ao Estado o quê? Garantir políticas públicas que permitam o prosseguimento desse projeto de país.

\section{Agronegócio, a urbanização do campo}

À medida que o agronegócio reivindica grandes parcelas das áreas produtivas do país para produzir "commodities", aprofunda-se o desequilíbrio entre os interesses do capital e a soberania alimentar e popular. Seja porque expropria quem produz comida, seja porque compele as pessoas a se aglomerarem em periferias e favelas nos grandes centros urbanos, que carecem de atenção do Estado e por isso veem diminuídas as suas condições de empregabilidade e acesso ao emprego e rendimento, o agronegócio diminui a diversidade e quantidade de produtos que compõem a alimentação no país (Mitidiero Junior, Barbosa, 2016) por um lado e, por outro, dificulta o acesso ao que é produzido.

A captura da subjetividade da chamada classe média (extrato social com rendimentos médios que lhe permite alguma segurança social e impulsiona o seu crescimento vinculado ao modo de vida do topo da pirâmide social) é essencial para o que Eric Fromm (1947) chamou de harmonização social. Assim, mesmo com a agricultura urbana a emergir como tática de reprodução social dos sujeitos que se encontram desassistidos pelo Estado nas cidades e com a agroecologia a impor-se como outro modelo de produção e de relação homem-natureza (Mendonça, 2012), o agronegócio é bem visto por grande parte da sociedade e continua a expandir-se. 
A questão é saber se existe a necessidade da população pobre passar a produzir na cidade e se o agronegócio além de não ter por objetivo garantir a soberania alimentar, ainda contamina solos, água, ar e até o leite materno, como indica o dossier da Associação Brasileira de Saúde Coletiva (F. Carneiro, 2015), por que motivo continua o agronegócio a expandir-se? E a resposta é: porque é moderno!

[...] Mesmo considerando que as particularidades locais e regionais provenientes dos tempos em que a agricultura predominava não desapareceram, que as diferenças daí emanadas acentuam-se aqui e ali, não é menos certo que a produção agrícola se converte num setor da produção industrial, subordinada aos seus imperativos, submetida às suas exigências. Crescimento econômico, industrialização, tornados ao mesmo tempo causas e razoes supremas, estendem suas consequências ao conjunto dos territórios, regiões, nações, continentes. Resultado: o agrupamento tradicional próprio à vida camponesa, a saber, a aldeia, transforma-se; unidades mais vastas o absorvem ou o recobrem; ele se integra à indústria e ao consumo de produtos dessa indústria. A concentração da população acompanha a dos meios de produção. O tecido urbano ${ }^{4}$ prolifera, estende-se, corrói os resíduos de vida agrária. Estas palavras, "tecido urbano", não designam, de maneira restrita, o domínio edificado nas cidades, mas o conjunto das manifestações do predomínio da cidade sobre o campo. Nessa acepção, uma segunda residência, uma rodovia, um supermercado em pleno campo, fazem parte do tecido urbano. (Lefebvre, 2006, p 14-15 - Grifo nosso)

A leitura Lefebvriana ${ }^{5}$ do urbano elucida o projeto de desenvolvimento modernizador em curso. Partindo desse entendimento, de facto o agronegócio é moderno. Cabe perguntar se esse projeto contempla os anseios do conjunto da sociedade brasileira, designadamente das populações socioeconomicamente menos favorecidas.

4. Os itálicos são do original.

5. Muito embora Lefebvre tenha sido um rigoroso e importante crítico do capitalismo, adotou algumas das principais premissas dessa narrativa urbano-capitalista como válidas para toda e qualquer sociedade, como se pode observar na citação. Todavia, o Brasil e outras nações comprovam que a ruralidade, entendida para além da localização espacial, compõe as estratégias de resistências dos sujeitos, inclusive na cidade, e fortalece-se muitas vezes em ações que constroem outros sentidos para a existência, sentidos para além do capital; tais práticas ficam evidentes em comunidades do México, da Bolívia, do Brasil, mas também em localidades da Europa, por exemplo. 


\section{Contradições do projeto de modernização no Brasil}

As dificuldades de refletir sobre o campo, no caso brasileiro, começam em definir o que se assume como campo. Os dados oficiais do Instituto Brasileiro de Geografia e Estatística consideram a definição dos municípios com base nas suas áreas urbanas e rurais. No entanto, mesmos os órgãos oficiais de investigação admitem que há restrições nessa definição.

Alguns desafios encontrados no caso dos cálculos para a situação de domicílio se mostraram intransponíveis. Primeiramente, é preciso atentar-se para a complexa relação de interdependência e complementariedade entre os espaços urbanos e rurais no Brasil e os conceitos adotados pelo Instituto Brasileiro de Geografia e Estatística (IBGE) que segue os preceitos estabelecidos pelas leis municipais para a definição do urbano e, por resíduo, do rural. Essa orientação político-administrativa dos municípios não permite um recorte espacial perfeito entre os espaços e, em alguns casos, expressa de forma distorcida a realidade e a diversidade deles. (FJP, PNUD, e IPEA, 2017)

Mesmo os novos critérios, supracitados, do IBGE para a definição de urbano e rural ainda deixam a desejar, pois carecem da adoção já há muito enunciada por Abramovay (2000) de critérios qualitativos. Há uma equiparação entre condições para a dignidade humana e urbanização.

Estabelece-se uma análise hegemónica. E hegemónica porque, entre outras coisas, é o que tem sido ensinado, por exemplo, nos currículos das escolas públicas do país.

Desde meados da década de [19]60, o espaço agrário brasileiro vem sendo "locus" para a realização crescente e contínua do capital urbano industrial. O desenvolvimento rural, previsto no Estatuto da Terra, com o apoio político e financeiro do Estado, seguiu a via da modernização agropecuária, alterando a base tecnológica da produção. Muito embora o processo não tenha se homogeneizado no tempo e no espaço, nos termos de Galvão (1995 p. 105) “...constituiu certamente o evento de maior expressão espacial e provavelmente de maior impacto sócio-econômico e político nos cenários agrícola, industrial e urbano do país..." Tal modelo incorporou pacotes tecnológicos (insumos químicos e maquinários) no agro nacional, sem reformular a estrutura fundiária, que contraditoriamente se fortaleceu, deixando em seu rastro, [sic] gravosos custos sócio-econômicos e ambientais. (Corrêa, Corrêa, Gerardi, 2001, p. 45-46 - Grifo dos autores). 
Esse entendimento de que o agronegócio causa problemas socio-ambientais e económicos, sobretudo, ao não permitir uma reforma agrária, precisa de ser confrontado com a leitura complementar, de que "A modernização das atividades agrícolas somada à atração natural exercida pelas grandes cidades, está na raiz do problema do êxodo rural no país" (Idem, p. 46). Alguns aspetos estão subentendidos nessa leitura e precisam ser explicadas. 1) O agronegócio está a correr bem e só é preciso prestar atenção a um ou outro dano que causa. 2) A concentração de terras é uma das consequências contraditórias da expansão do agronegócio. 3) A cidade exerce uma atração natural sobre as populações do campo. 4) Houve um êxodo rural no país.

Outra leitura sobre estes pontos é:

1) O agronegócio é uma aglutinação complexa de setores da sociedade, cuja primazia está nas empresas agroquímicas como Bayer, Dupont, Monsanto, e que no Brasil se une a uma intrincada elite agrária que detém poder político-institucional, que remonta aos períodos coloniais, cuja força central está justamente no controlo fundiário do país, como referem A. L. Castilho (2012) e V. N. Leal (2012). Alguns dos seus piores efeitos, como a concentração fundiária, compõe a própria razão de ser do agronegócio no Brasil, uma vez que lhe confere mais poder e suporta a sua sustentação como modelo para o campo.

2) Sendo objetivo da expansão do agronegócio, e não um desvirtuamento, a concentração de terra e rendimentos é contraditória à reforma agrária e por isso a bancada ruralista trabalha no Congresso Nacional para a paralisar totalmente, nos seus mínimos avanços, bem como para que a expulsão e a expropriação dos sujeitos que resistem no campo seja permitida e realizada pelo Estado, ou pelo menos para que o Estado não intervenha quando os próprios agentes do agronegócio precisam de ameaçar, expulsar e mesmo matar quem resiste (EPOCA, 2017).

3) Ao negar que a urbanização-industrialização-modernização se converteu no conteúdo da narrativa do desenvolvimento e que, para tanto, foram

6. Para informações mais detalhadas da atuação da bancada ruralista no Congresso Nacional, bem como sua influência em diferentes dimensões da vida no país, consultar o blogue De Olho nos Ruralistas, disponível em $<$ https://deolhonosruralistas.com.br/> 
mobilizados todos os meios, desde publicidade, passando pelo cinema até às políticas públicas, essa análise da "atração natural" das cidades escamoteia a disputa sóciossimbólica existente e que influi na formação da conceção de mundo dos diversos sujeitos (Lima, 2005; Carneiro, 1998). Por isso mesmo, porque os sujeitos ainda não estão convencidos de que esta é a melhor, e quiçá única, forma de chegar ao desenvolvimento social, precisam de ser silenciados.

4) Nunca houve um êxodo rural no Brasil. Ou seja, mesmo diante de todo o aparato mobilizado para convencer a população nacional de que desenvolver é urbanizar-industrializar, pois isso representa modernização, não fosse a falta de políticas públicas que garantem as condições para os sujeitos permanecerem nos seus territórios tendo acesso àquilo que lhes cabe de direito, não haveria um fluxo tão grande de pessoas para os centros urbanos à procura de melhores condições de vida, como demonstram as populações que resistem no campo. E o sentido de êxodo suaviza o processo sistemático de expropriação e expulsão que continua contra quem vive no campo.

Os governantes nacionais, bem como o Estado brasileiro, ao partilharem a ideia de que o desenvolvimento só será alcançado com a plena modernização de todo o território administrativo nacional, colocam-se em xeque no xadrez da gestão do interesse público. Se por um lado a aproximação de setores que compõem a elite que comanda o Brasil, formal e informalmente, utiliza diversos instrumentos de convencimento de que esse é o melhor caminho para todos, por outro, têm que lidar com os desdobramentos reais desse modelo para a população, sendo que para negar esta realidade o Estado tem-se coibido de cumprir acordos internos e internacionais (Carvalho, Ribas, Benitez, 2017).

A figura 1 demonstra como o agronegócio obtém mais de $80 \%$ dos recursos públicos para o seu processo produtivo enquanto a agricultura familiar fica com algo próximo a $15 \%$. E, apesar disso, é a agricultura familiar que emprega $74 \%$ da mão-de-obra no campo e produz $70 \%$ da comida que chega à mesa do brasileiro. Se o trabalho análogo à escravização for adicionado, fica ainda mais evidente o antagonismo do agronegócio com os direitos constitucionais ao território e à vida digna, uma vez que os resgates de seres humanos nessas condições são recorrentes em empresas ligadas ao agronegócio no país 
(WAGNER, 2016). O moderno revela-se bastante atrasado historicamente nas suas práticas!
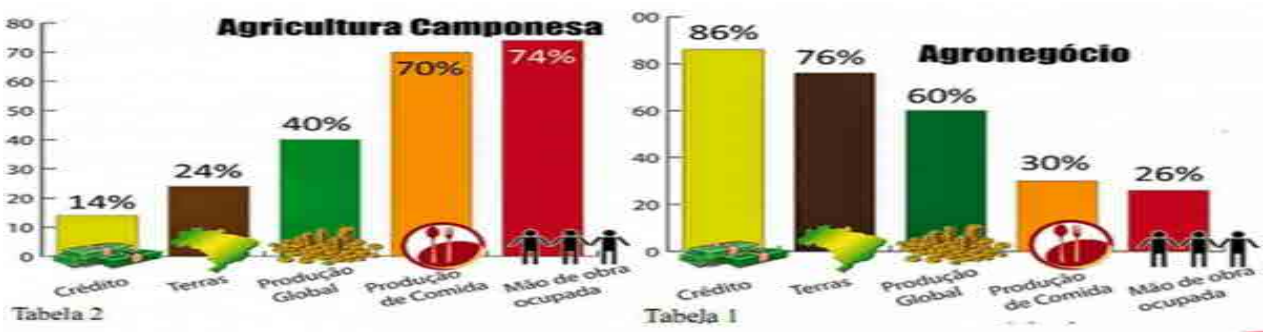

Figura 1. Produção e financiamento para o campo brasileiro. Fonte: MDA, 2016.

A figura 2 aponta a grande lacuna na medição dos Índices de Desenvolvimento Humano Municipal ( IDHM $^{8}$ ) nos dados do censo 2010 entre os municípios que se situam no campo e os que se situam na cidade. Mostra a média de cada Unidade Federativa (UF) e desagrega para cada UF, domicílios urbanos e rurais.

Percebe-se que a média só é muito alta para o Distrito Federal, onde está localizada a capital do país. É a única UF onde os domicílios rurais têm IDHM alto, o que somado ao facto de que apenas domicílios rurais têm IDHM muito baixo e baixo comprova a falta de investimento público em políticas públicas que garantam qualidade de vida para quem reside no campo. Este é o melhor momento para reafirmar: se o Estado construísse critérios nacionais pautados nas diferenças reais entre campo e cidade, como as analisadas por Sorokin, Zimmerman e Galpin (1981), provavelmente o IDHM rural subiria, pois muitos municípios brasileiros confrontados com quesitos como densidade populacional, número absoluto da população, homogeneidade e heterogeneidade das populações, entre outras, seriam considerados rurais, em suas diversas aceções, como salienta Abramovay (2000).

7. Ministério do Desenvolvimento Agrário, extinto pelo governo federal após o golpe parlamentar ocorrido em abril de 2016.

8. O IDHM varia entre 0 e 1 , sendo que quanto mais perto de 1 melhor as condições de vida naquele município. 
Mapa 3: IDHM desagregado por situação de domicílio, por UF, para 2010

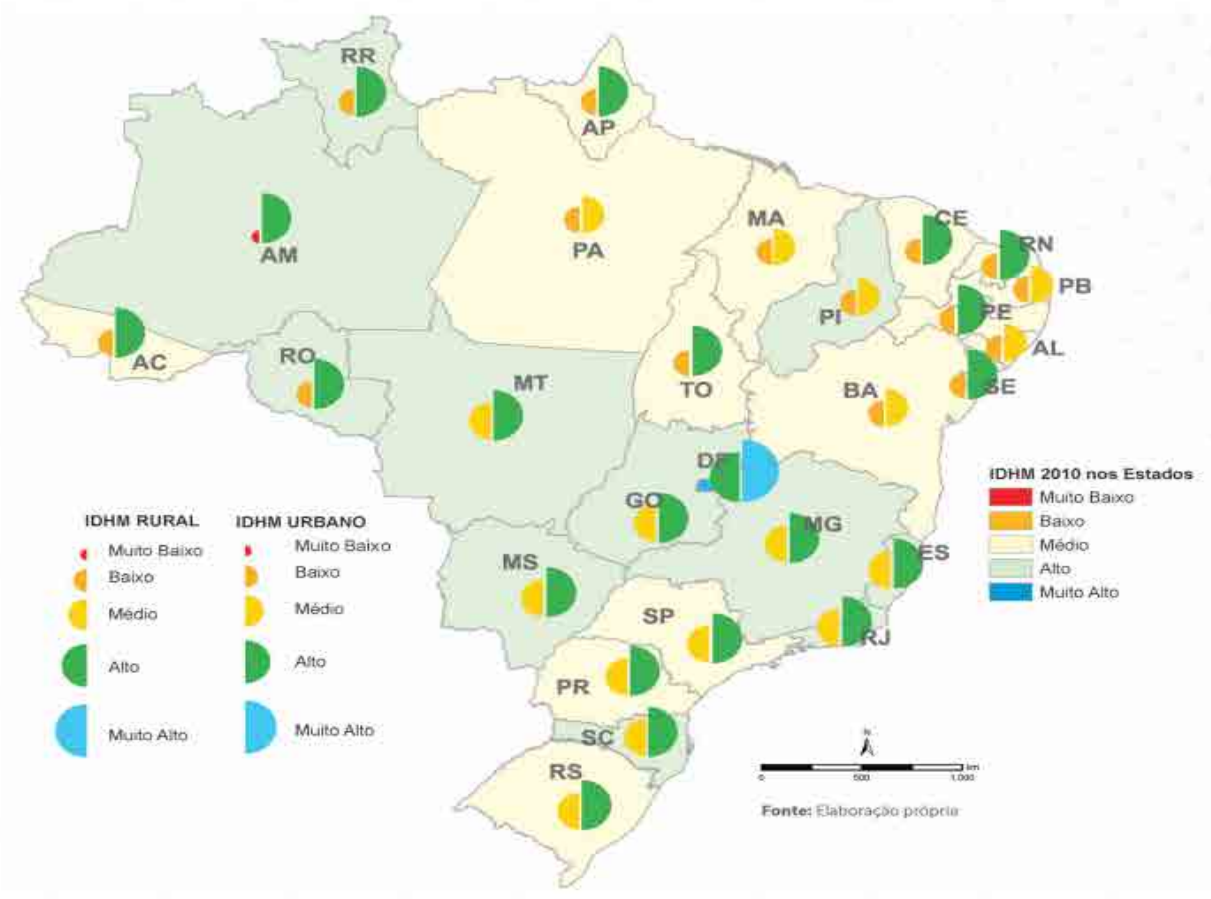

Figura 2. IdHM por UF e situação do domicílio. Fonte: ( FJP, PNUD, e IPEA, 2017).

Muito embora a diferença entre a expectativa de vida na cidade e no campo não seja tão grande quanto a disparidade do IDHM, os dados relativos à educação e ao rendimento, apresentados na figura 3, confirmam que essa busca por uma modernização urbanizadora e industrializante acaba por privar as populações que residem no campo dos seus direitos fundamentais, como a educação. E num país que prima pela industrialização da alimentação e que vê áreas destinadas ao cultivo de alimentos serem destinadas às plantações de "commodities", o não acesso da população rural ao rendimento é consequentemente uma violação da sua capacidade de alimentação, visto que mesmo a produção para autoconsumo, como tem sido historicamente feita por essas populações, é dificultada com o avanço e o assédio do agronegócio.

Não obstante o menosprezo do Estado brasileiro em relação às populações do campo, esse discurso de que a cidade exerce uma atração natural para os sujeitos é desmontado na resistência destas populações. Mesmo expostas a um quadro de insegurança de todas as ordens, nomeadamente económica, social, ambiental e sanitária, quem constrói a sua vida no campo continua a 
lutar pelo direito de permanecer nos seus territórios. E ao fazê-lo choca com a expansão do agronegócio, os conflitos são as consequências. E a escalada da violência no campo remonta a tempos coloniais. É difícil imaginar que as informações da figura 4 dizem respeito a um país que está entre as 10 economias mais importantes do mundo.

Se o crescimento económico não se reverte em desenvolvimento social, tendo pelo contrário concentrado riqueza, terra e poder, é o próprio sentido do desenvolvimento que deve, então, ser questionado, como já observaram Peet (2007), Gomez (2007) e Pires (2007). Assim, seja pelo modernismo crítico, seja pelo não-desenvolvimento, seja pelo desenvolvimento territorial, é consenso entre os críticos desse projeto de sociedade que os conflitos só podem ser dirimidos mudando-se estruturalmente a lógica das políticas públicas. Ao que acrescentamos: valorizar a vida no campo, no Brasil, é ser contra o projeto capitalista de sociedade representado pelo agronegócio como demonstram os relatórios citados e os dados levantados e sistematizados pelo Núcleo de Estudos, Pesquisas e Projetos da Reforma Agrária - NERA. ${ }^{9}$

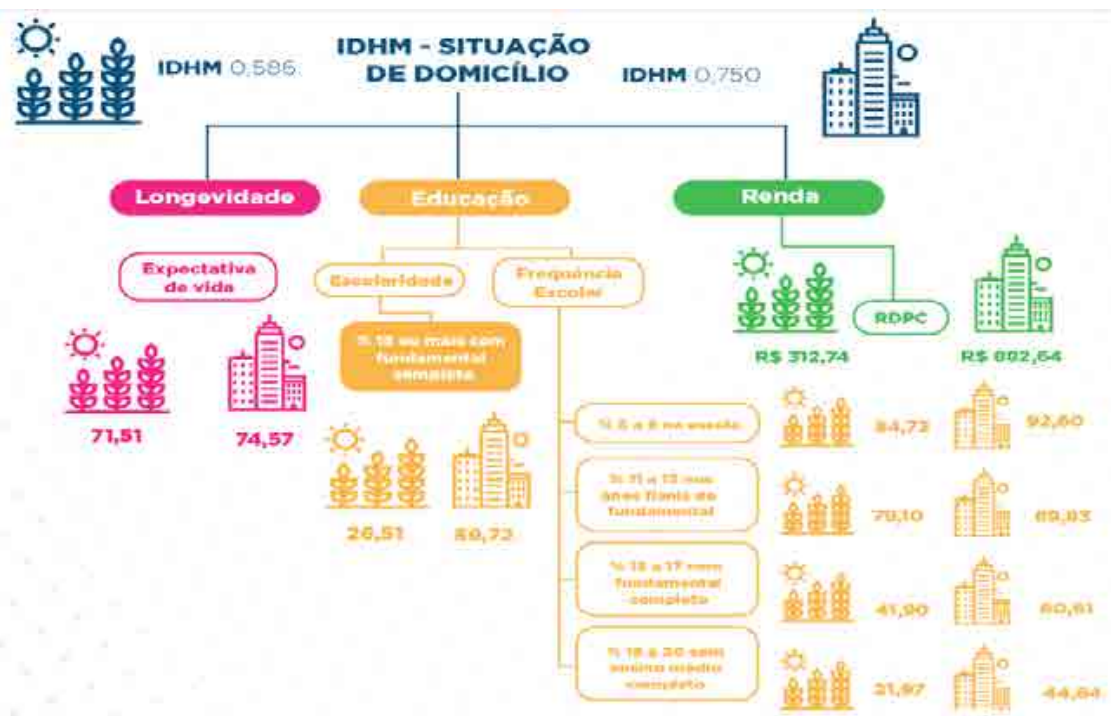

Figura 3. Dados sobre expectativa de vida, educação e renda por situação de domicílio para o Brasil em 2010. Fonte: ( FJP, PNUD, e IPEA, 2017).

9. Disponível em http://www2.fct.unesp.br/nera/ 
Um país que depende da produção camponesa para sustentar a sua população e seguea criar dificuldades à continuação e ao crescimento dessa produção, está a colocar em xeque, como dito anteriormente, não só a soberania alimentar dessa população, mas, de forma mais ampla, a própria vida. Isso porque embora as contradições desse modelo atinjam mais rápida e fortemente as comunidades pobres, tanto no campo quanto na cidade, toda a sociedade paga pelo estado de exceção impetrado no país. Folgado (2016) utiliza a gestão dos agrotóxicos para demonstrar como o Brasil vive num estado de exceção, que gera um envenenamento sistemático e generalizado da população.

Respondendo a esse quadro de intoxicação, a sociedade, nomeadamente a partir dos movimentos sociais e de investigações e práticas vinculadas às universidades, tem apostado na agroecologia. Os movimentos sociais de luta pela terra, bem como os que trabalham com a população que já reside no campo, como o Movimento Camponês Popular (MCP), têm levado a agroecologia para dentro das propriedades rurais. A agroecologia impõe-se como pauta do debate social amplo. Todavia, ela tem sido silenciada. Ao não apresentar para a sociedade uma alternativa ao agronegócio, o Estado brasileiro está a dar o seu aval ao avanço deste modelo e suas consequências, das quais se destacam os conflitos.

$\mathrm{Na}$ figura 4 percebe-se a escalada da violência no Brasil. Se por um lado os conflitos totais em 2016 são praticamente os mesmos de 2007, por outro lado o número de pessoas envolvidas e a violência, cujo ápice são os assassinatos, cresceram contundentemente. A figura 5 sintetiza os dados para 2016, revelando que quase 2500 pessoas por dia envolveram-se em conflitos no campo naquele ano. 


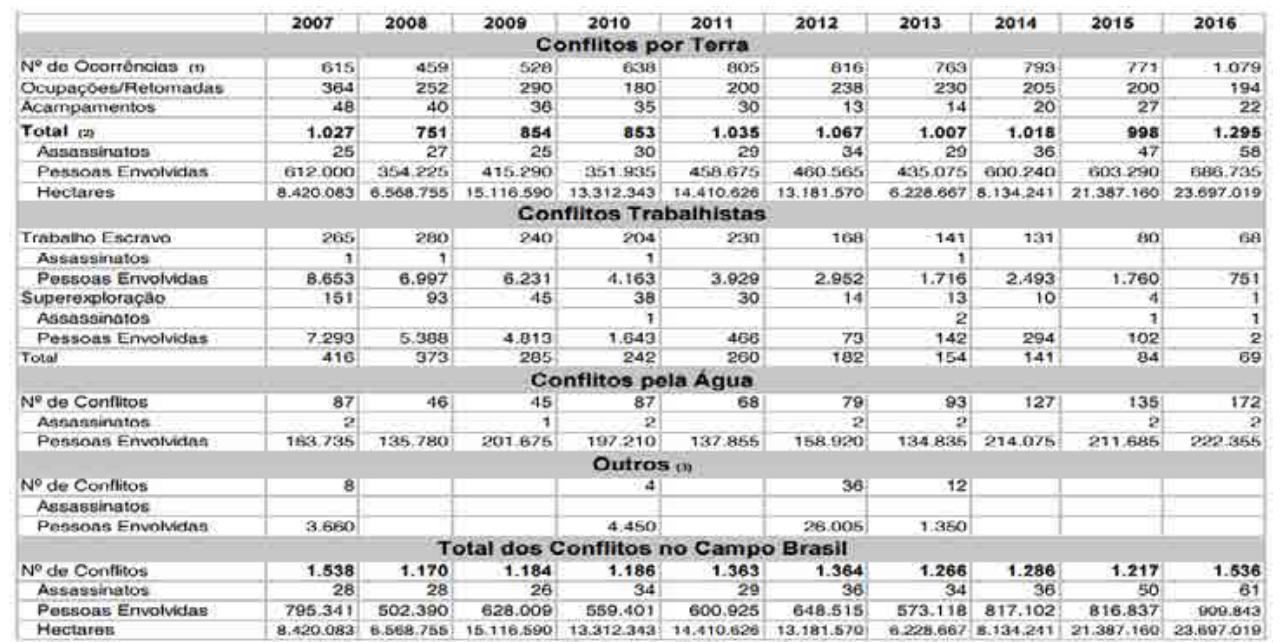

in Os dados do $n^{\circ}$ de ocorréncias referem-se aos despejos e expulsóes, amesças de despejos e expulsóes, bens destruídos e pistotagem.

(2) Em 2016, foram registrados 1.295 ocorréncias de contito por terra. Numa mesma àrea, urn conflito pode ter descobramentos diversos Gacta um deles corresponde a uma ocorréncia. Neste ano, as areas ou localidades em conflto somam 939. Para saber as Áreas em Conflito, ver no site www.cptnacional.org.be.

(9) Outros: Confitios em Tempos de SecA, Politica Agricola o Garimpo.

Figura 4. Dados dos conflitos no campo entre 2007 e 2016.

Fonte: Canuto, Luz, Andrade, 2016.

\begin{tabular}{|r|r|r|}
\hline & \multicolumn{2}{|c|}{ Brasil } \\
\hline & Conflitos & Pessoas \\
\hline Terra & 1295 & 686735 \\
\hline Trabalho & 69 & 753 \\
\hline Água & 172 & 222355 \\
\hline Total Brasil & 1536 & 909843 \\
\hline
\end{tabular}

Figura 5. Dados dos conflitos no campo para 2016.

Fonte: Canuto, Luz, Andrade, 2016.

Pensar sobre a violência como desdobramento desse projeto de sociedade e de país exige considerar a violência não só contra os que resistem no campo, mas também contra os que foram levados para as cidades, sobretudo, para os grandes centros. Essa violência atinge todos os que não são o sujeito do desenvolvimento moderno. Que esse sujeito virtual é branco, heterossexual e bem-sucedido economicamente é um facto incontestado; os dados de violência contra a população negra, contra as mulheres, população LGBT e transexuais 
são provas cabais e facilmente acessíveis. Um passeio pelos grandes centros urbanos e um olhar atento para o mercado de trabalho revela que embora a população negra seja superior a 50\% no país, está localizada essencialmente em periferias e favelas e que há uma feminização da pobreza ( FJP, PNUD, e IPEA, 2017). O fosso entre os dados do IDHM para a população negra e os dados ajustados para as mulheres vistos nas figuras 6 e 7 confirmam esse colapso social.

Gráfico 1: Evolução do IDHM e desagregaçōes para o Brasil, 2000 c 2010

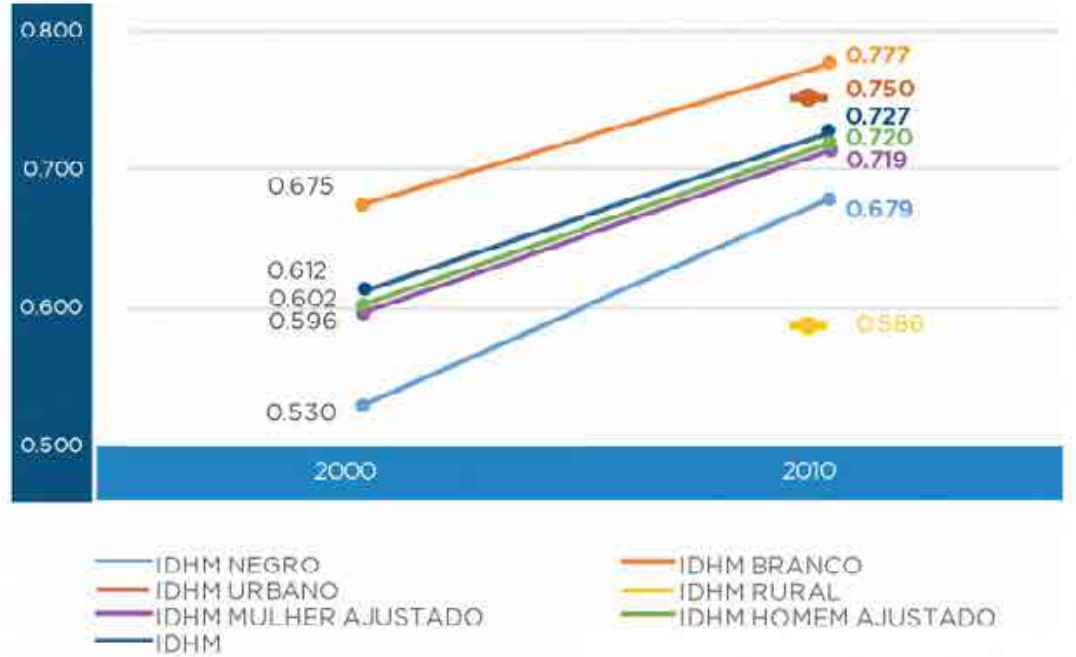

Figura 6. Comparação do IDHM para o Brasil nos anos de 2000 e 2010.

Fonte: (FJP, PNUD, e IPEA, 2017).

\begin{tabular}{|c|c|c|c|c|c|c|c|}
\hline & & & IDHM & $\begin{array}{l}\text { Esperancas } \\
\text { of Vidh io } \\
\text { Nuscer }\end{array}$ & 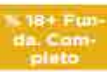 & 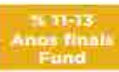 & Renda \\
\hline \multirow{4}{*}{ COR } & Negro & 2000 & 0.530 & 86, 6 & 3003 & $\tan \alpha$ & RS 322730 \\
\hline & Branco & 2000 & 0,675 & तो & Atrea: & रूobe: & R\$ 806,36 \\
\hline & Negro & 2010 & 0,679 & 7822 & 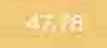 & 35,30 & R\$ 508,90 \\
\hline & Branco & 2010 & 0,777 & 76,5 & 62121 & 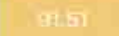 & R5 $1.097,00$ \\
\hline \multirow{4}{*}{$\begin{array}{l}\text { Sexo } \\
\text { Ajustado } \\
\text { a Renda } \\
\text { Trabalho }\end{array}$} & Mulher & 2000 & 0,596 & 318 & $4 x 60$ & destre & R5 $939 \pi 0$ \\
\hline & Homem & 2000 & 0,602 & 647 & $34 \times 5$ & 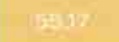 & $\operatorname{RS} 1.42230$ \\
\hline & Muther & 2010 & 0,720 & XKB & 50.7 & Inepses & R\$ 1059,30 \\
\hline & Homem & 2010 & 0,719 & 6935 & Axtan & $65 \times 8$ & RS 1470,73 \\
\hline \multirow{2}{*}{$\begin{array}{c}\text { Situ- } \\
\text { açāo de } \\
\text { Domicilio }\end{array}$} & Rural & 2010 & 0,586 & $2 \pi .5$ & 2659 & Fato & R\$ 312.74 \\
\hline & Urbana & 2010 & 0,750 & 746. & Giger & sages & R\$ 882,64 \\
\hline
\end{tabular}

Figura 7. IDHM desagregado e com subíndices para 2000 e 2010. Fonte: ( FJP, PNUD, A IPEA, 2017). 
Sendo o Brasil signatário de diversos tratados internacionais, para além de sua própria Constituição Federal, tais sujeitos têm direito e condições de reclamarem o cumprimento de tais tratados, como forma de garantir Direitos Humanos, e, portanto, dignidade (Almeida, Pereira, 2013). Muitas dessas exigências são simplesmente invisibilizadas, e praticamente ignoradas, pelo Estado brasileiro no seu projeto de desenvolvimento modernizador. Para alguns sujeitos, como as Populações Tradicionais, há algumas informações que não são divulgadas e debatidas, e consequentemente não se revertem em proteção social; para outros, nem isso, como é o caso da população transexual. Se o Brasil é o país mais transfóbico do mundo, como deve ser a vida de um sujeito transexual no campo, por exemplo? Por isso, o relatório publicado pela FJP, PNUD, e IPEA, (2017) é muito preciso quando reforça a necessidade de dados que revelem essas realidades, bem como de que esses dados subsidiem políticas públicas que garantam os direitos constitucionais.

Nas áreas rurais brasileiras, a população também apresentou significativa melhoria nos seus índices de desenvolvimento humano. Contudo, apresentam resultados bastante díspares dos patamares observados para as cidades, principalmente quando olhamos para as estatísticas de educação e rendimento.

Com isso, entende-se que, para continuar a reduzir as desigualdades, é fundamental que as métricas de desenvolvimento humano sejam complementadas e intercruzadas com outras métricas de bem-estar, desagregadas e atuais, a fim de alcançar uma compreensão melhor e mais exata da realidade das populações menos favorecidas. Essa compreensão é imprescindível para a elaboração e focalização de políticas públicas. (FJP, PNUD, e IPEA, 2017, p. 40-41)

A discrepância entre o IDHM urbano e rural não poderia ser mais representativa daquilo que se processa no Brasil. O crescimento das populações rurais semeia as bases do enfraquecimento do agronegócio. As jazidas minerais, bem como as áreas passíveis de serem incorporadas nesse modelo moderno de agricultura estão nos territórios destas comunidades que não podem ter uma vida digna, porque isso fragiliza os argumentos dessa expansão.

A naturalização do referencial urbano, que apaga os sentidos da vida rural para além do compromisso com a reprodução ampliada do capital, tem uma série de desdobramentos. A opção foi demonstrar a face mais perversa, que 
caminha para o extermínio de comunidades rurais inteiras, bem como atinge sujeitos que não são o padrão estético-social desse projeto.

\section{Questões para promover o aprofundamento da reflexão}

O Estado brasileiro emprega vultuosas quantias de dinheiro para sustentar o seu projeto para o campo. Foi por meio de subsídios do Banco Nacional de Desenvolvimento Econômico e Social (BNDS), por exemplo, que a J\&F, grupo económico que responde pela maior produção de proteína animal do mundo, conseguiu deixar de ser uma empresa nacional e se transformar no que é hoje. Se os investimentos fossem equalizados, o campo brasileiro seria ainda mais diverso, as muitas comunidades que lá vivem teriam seus direitos constitucionais assegurados, e o país teria uma produção agrícola ainda mais rica em importância económica e variedade.

A existência de trabalho escravo na cadeia produtiva do agronegócio expõe a limitação e fragilidade desse projeto modernizador. A não-garantia por parte do Estado de direitos básicos da população rural não é devida à falta de capacidade económica. É, antes, a consolidação, perversa, de um projeto muito bem definido e levado a cabo. Essa atuação reforça a leitura de Lenin (2007) sobre o papel do Estado.

Não faltam evidências de que realizar a Reforma Agrária, mexendo na estrutura fundiária, cria condições para a valorização da vida no campo e constrói concretamente condições para pensar outro projeto de país, para o campo e para a cidade, nomeadamente a partir da produção da alimentação saudável, síntese das contradições do capitalismo brasileiro.

Vincular direitos fundamentais aos conceitos de cidadania, urbanização, civilização (o que é próprio da cidade) é concordar tacitamente com o projeto de sociedade urbano-capitalista que nega o campo-rural como local e conteúdo de vida digna, designadamente nos meandros das idiossincrasias do capitalismo brasileiro.

Reivindicar a democratização dos meios de comunicação, debater publicamente o sentido e os conteúdos de um projeto popular de desenvolvimento social, fortalecer os movimentos sociais e demais formas de organização social, para que sejam definidos outros parâmetros para medir a qualidade de 
vida e, portanto, como e onde se investirão os recursos públicos, são desafios essenciais. E para além da negação dessa leitura simplista de urbano-moderno x rural-atrasado, cujo desdobramento é a valorização das cidades em detrimento do campo, inclusive transformando virtualmente espaços com características rurais em cidades de forma arbitrária, é preciso ampliar os efeitos imediatos do agronegócio sobre os bens naturais comuns.

Se levado a debate público, o envenenamento sistemático do ar, da água, do leite materno, da alimentação diária, entre outros, constantes no Dossiê Abrasco, certamente levará a população brasileira a repensar as condições às quais já está submetida. E fazer a ligação entre esse quadro e o atual projeto de sociedade ancorado nesse projeto é o papel cumprido pelo fortalecimento da educação do campo e, por isso, tem sido combatida pelo agronegócio, com o fechamento de milhares de escolas rurais nos últimos anos.

Por fim, deixar que o campo seja definitivamente esvaziado dos seus ocupantes históricos e dos novos sujeitos que requerem o direito de voltar à terra, é perverso porque deteriora as condições de existência desses sujeitos, por um lado, e é cínico porque cria as condições de uma fuga das consequências traumáticas da hiper-urbanização das megalópoles com uma busca reificada pelas condições características do rural. Basta mencionar que no Brasil o segmento de Turismo Rural cresce acima da média, mesmo em momentos de crise. Como apontou Masi (2000) o turismo/lazer converte-se em condição para suportar uma vivência privada de sentido produtivo para além do capital.

\section{Referências}

Abramovay, R. (2000). «Do setor ao Território: funções e medidas da ruralidade no desenvolvimento contemporâneo». In: Inter-relações entre as transformações demográficas e a agenda social. Texto para discussão IPEA. - São Paulo/Rio de Janeiro: IPEA.

Almeida, P. W. \& Pereira, M. F. L. (2013). «Revisitando os efeitos da assinatura de um tratado internacional: da obrigação de boa-fé à sujeição internacional do Estado». Revista de Direito GV. São Paulo. 9 (1) Jan.-Jun., pp. 171-198. 
Araujo, C. (2017). «A atuação do Estado neodesenvolvimentista na reorganização do capitalismo no campo brasileiro: o agronegócio como entrave da reforma agrária». In: Carvalho, E., Ribas, L. O. \& Benitez, C. (Org.). A luta pela terra, água, florestas e o direito. Goiânia: Kelps.

BRANDão, C. R. (2007). «Tempos e espaços nos mundos rurais do Brasil». Ruris, Vol. 1 N. 1, pp. 37-64.

Campos, A. (2014). «Movimento em estruturas "socioespaciais": em busca dos sujeitos subalternos». In: Silva, C. A.; Campos, A. \& Modesto, N. S. A., Por uma geografia das existências: movimentos, ação social e produção. Rio de Janeiro: Consequência.

Canuto, A., Luz, C. R. S. \& Andrade, T. V. P. (Org.) (2016). Conflitos no campo - Brasil 2016. Goiânia: СТP.

Castilho, A. L. (2012). O partido da terra: como os políticos conquistam o território brasileiro. São Paulo: Contexto.

Castilho, D. (2011). «Os Sentidos Da Modernização». Boletim Goiano de Geografia, 30(2), pp. 125-140. Recuperado de https://doi. org/10.5216/bgg.v30i2.13285

— (2016). Modernização territorial e redes técnicas em Goiás. Goiânia: UfG.

Castilho, D. \& Chaveiro, E. F. (2010). «Por uma análise territorial do Cerrado». In: Pela, M. \& Castilho, D. (Org.), Cerrados: perspectivas e olhares. Goiânia: Editora Vieira.

Carneiro, F. F. (Org.) (2015). Dossiê abrasco: um alerta sobre os impactos dos agrotóxicos na saúde. Associação Brasileira de Saúde Coleti$v a-A B R A S C O$. Recuperado de https://doi.org/10.1016/B978-84-4582066-7.00003-3

Carneiro. M. J. (1998). Ruralidade: novas identidades em construção. Recuperado de http://bibliotecavirtual.clacso.org.ar/ar/libros/brasil/ cpda/estudos/onze/zeze11.htm

Carvalho, E., Ribas, L. O. \& Benitez, C. (Org.) (2017). A luta pela terra, água, florestas e o direito. Goiânia: Kelps.

Cerqueira, D. et Al. (2017). Atlas da violência no Brasil 2017. Rio de JaneirO: IEPA, FBSP.

Chaveiro, E. F. \& Calaça, M. (2012). «Por uma abordagem territorial do Cerrado goiano». In: Geografia da e para a cooperação ao desenvolvimento territorial: experiências brasileiras e italianas. Saquet, M.; Dansero, E. \& Candiotto, L. (Orgs.). São Paulo: Outras Expressões.

Correa, J. M., Correa, W.K. \& Gerard, L. H. de O. (2001). «A problemática da definição do espaço rural e urbano. Mudanças no espaço 
rural e práticas institucionais: o exemplo da ilha de Santa Caarina». In: Geografia. Vol. 25 (1) - Rio Claro.

Epoca (2017). Mudanças nas regras do trabalho escravo se juntam a outras benesses concedidas à bancada ruralista. Recuperado de http:// epocanegocios.globo.com/Brasil/noticia/2017/10/mudanca-nas-regras-do-trabalho-escravo-se-junta-outras-benesses-concedidas-bancada-ruralista.html

FJP, PNUD, \& IPEA (2017). Desenvolvimento Humano para além das médias. Recuperado de http://www.ipea.gov.br/portal/images/stories/PDFs/ livros/livros/170510_desenvolvimento_humano_para_alem_das_ medias.pdf

Folgado, C. A. (2012). Agrotóxicos e o estado de exceção: a suspensão da legislação de agrotóxicos em atenção aos interesses do agronegócio. In: Souza, M. M. O. \& Folgado, C. A. (Org.), Agrotóxicos: violações socioambientais e direitos humanos no Brasil. (pp. 255-283) Anápolis: UEG.

Fromm, E. (1947). Análise do homem. Trad. Octavio Alves Velho. São Paulo: Círculo do Livro S/A, S/D (1947).

Gómez, J. R. M. (2007). Desenvolvimento em (des)construção: provocações e questões sobre desenvolvimento e geografia. In: Fernandes, B. M.; Marques, M. I. M. \& Suzuki, J. C. (Orgs.), Geografia agrária: teoria e poder (pp. 39-54). São Paulo: Expressão Popular.

Harvey, D. (2011). O enigma do capital: e as crises do capitalismo. Trad. João Alexandre Peschanski. São Paulo, SP: Boitempo.

IBGE (2017). Classificação e caracterização dos espaços rurais e urbanos do Brasil: uma primeira aproximação. Rio de Janeiro: IBGE.

Leal, V. N. (2012). Coronelismo, enxada e voto: município e o regime representativo no Brasil. $7^{\mathrm{a}}$ ed. São Paulo: Cia das Letras.

Lefebvre, H. (1979). Sociologia de Marx. Trad. Dias, C. R. A. Rio de Janeiro: Forense-Universitária.

— (2006) O direito à cidade. São Paulo: Centauro

LENIN, V. I. (2007). O Estado e a revolução: o que ensina o marxismo sobre o Estado e o papel do proletariado na revolução. Trad. revista Aristides Lobo. São Paulo: Expressão Popular.

Lima, E. N. (2005). «Novas ruralidades, novas identidades. Onde?» In: Moreira, R. J. (Org.), Identidades sociais - ruralidades no Brasil contemporâneo. Rio de Janeiro: DP\&A Editora.

MASI, D. D. (2000). O ócio criativo: entrevista a Maria Serena Palieri. Trad. Lea Manzi. Rio de Janeiro: Sextante. 
Mendonça, M. R. (2015). «As transformações espaciais no campo e os conflitos pelo acesso à terra e à água: as novas territorialidades do agrohidronegócio em Goiás». Revista Pegada, Vol. 16. № Especial.

Mendonça, M. R. (Org.) (2012). Agroecologia: práticas e saberes. 2. ${ }^{a}$ ed. Catalão: Gráfica Modelo.

Mendonça, M. R. \& THOMAZ JUNIOR, A. (2004). «A modernização da agricultura nas áreas de Cerrado em Goiás (Brasil) e os impactos sobre o trabalho». Investigaciones Geograficas, Boletín del Instituto de Geografia. unAm. N. 55, pp. 97-121.

Mitidiero Junior, M. A. (2017). «Violência no Brasil em tempos de golpe». Boletim Dataluta (NERA). No 114.

Mitidiero Junior, M. A. \& Barbosa, H. J. N. (2016). "Quem produz comida para os brasileiros? 10 anos do censo agropecuário 2006, feliz aniversário campesinato». In: Anais do XXII Encontro Nacional de Geografia Agrária. Sergipe: UFs.

Охғам(2017). A distância que nos une: um retrato das desigualdades brasileiras. Recuperado de https://www.oxfam.org.br/o-que-fazemos/ campanha-contra-as-desigualdades

Peet, R. (2007). «Imaginários de desenvolvimento». In: Fernandes, B. M.; Marques, M. I. M. \& Suzuki, J. C. (Orgs.), Geografia agrária: teoria e poder (pp. 19-38). São Paulo: Expressão Popular.

Pessoa, V. L. (1988). Ação do Estado e as transformações agrárias no Cerrado das zonas de Paracatu e alto Paranaíba/ MG. Dissertação de mestrado. UNESP: Rio Claro. $237 \mathrm{f}$.

PIRES, E. L. S. (2007). «As lógicas espaciais e territoriais do desenvolvimento: delineamento preliminar dos aspectos históricos, teóricos e metodológicos». In: Fernandes, B. M.; Marques, M. I. M. \& Suzuki, J. C. (Orgs.), Geografia agrária: teoria e poder (pp. 55-82). São Paulo: Expressão Popular.

SAles, A. (2017/Maio/11). O Cerrado - e a campanha da fraternidade de 2017. Recuperado de http://altairsalesbarbosa.blogspot.com. br/2017/02/o-cerrado.html

SAntos, M. (2008). O Espaço dividido: os dois circuitos da economia urbana dos países em desenvolvimento. Trad. Mirna T. R. Viana. $2^{\mathrm{a}}$ ed. São Paulo: Editora da Universidade de São Paulo.

Secchi, L. (2010). Políticas públicas: conceitos, esquemas de análise, casos práticos. - São Paulo: Cengage Learning.

Sorokin, P. A.; Zimmerman, C. C.; Galpain, C. J. (1981). «Diferenças fundamentais entre o mundo rural e o urbano». In: Martins, J. S., Introdução crítica à sociologia rural. São Paulo: Hucitec. 
WAGNER, A. (2016). «As ocorrências de trabalho escravo relativizam a visão triunfalista da chamada "modernização da agricultura"». In: Canuto, A.; Luz, C. R. S.; Andrade, T. V. P. (Orgs.). Conflitos no campo Brasil 2016 (pp. 134-141). Goiânia: СтP. 